\title{
СРАВНИТЕЛЬНЫЙ АНАЛИЗ ФАРМАКОЛОГИЧЕСКОЙ ЭФФЕКТИВНОСТИ АНГИОПРОТЕКТОРНЫХ ПРЕПАРАТОВ В ТЕРАПИИ СИНДРОМА ЗАДЕРЖКИ РОСТА ПЛОДА
}

\author{
(С) Клычева О.И., Хурасева А.Б.
}

Кафедра акушерства и гинекологии Курского государственного медицинского университета, Курск E-mail: lyolya.klichiova@yandex.ru

\begin{abstract}
Фетоплацентарная недостаточность является важной проблемой акушерства, и приводит к формированию синдрома задержки роста плода. Стандартной схемы лечения существовать не может вследствие индивидуального сочетания этиологических факторов и патогенетических механизмов развития данного осложнения. Проведено ретроспективное и проспективное обследование 80 беременных женщин на сроках гестации от 28 до 36 недель. При анализе результатов инструментальных методов исследования после фармакологической коррекции выявлено равноценное улучшение показателей гемодинамики как в маточных сосудах, так и в артерии пуповины плода, что обусловлено действием препарата «Флебодиа 600» ${ }^{\circledR}$, тогда как «Пентоксифиллин» ${ }^{\circledR}$ оказывает частичное положительное действие на маточный и плацентарный кровоток.

Ключевые слова: фетоплацентарная недостаточность, синдром задержки роста плода, флебодиа 600, пентоксифиллин, ангиопротектор.

\section{COMPARATIVE ANALYSIS OF PHARMACOLOGICAL EFFICACY OF ANGIOPROTECTIVE AGENTS IN THE TREATMENT OF FETAL GROWTH RETARDATION SYNDROME Klycheva O.I., Khuraseva A.B.}

Department of Obstetrics and Gynecology of Kursk State Medical University, Kursk

Fetoplacental insufficiency is an important problem of obstetrics, and this pathological condition leads to the development of fetal growth retardation syndrome. Standard treatment regimens cannot be available due to a combination of individual etiological factors and pathogenetic mechanisms of developing this complication. The retrospective and prospective survey of 80 pregnant women in terms of gestation from 28 to 36 weeks was performed. When analyzing the results of instrumental research methods after pharmacological correction, an equivalent improvement in hemodynamic parameters was revealed in both the uterine vessels and in the artery of the umbilical cord, which is due to the action of the preparation «Flebodia 600» ${ }^{\circledR}$, whereas «Pentoxifylline» ${ }^{\circledR}$ has a partial positive effect on uterine and placental blood flow.
\end{abstract}

Keywords: fetoplacental insufficiency, fetal growth retardation syndrome, Flebodia 600, Pentoxifylline, angioprotector.

Фетоплацентарная недостаточность (ФПН) является важной проблемой не только акушерства, перинатологии, педиатрии, но и нации в целом, являясь одной из основных причин перинатальной заболеваемости и смертности. Исследования последних лет показали, что ФПН представляет собой симптомокомплекс, который сопровождает практически все осложнения беременности и способствует возникновению гипоксии и, как следствие, формированию синдрома задержки роста плода (СЗРП) в 60\% случаев. По данным ряда авторов, частота ее колеблется от $45 \%$ до $86 \%$ и имеет четкую тенденцию к росту, перинатальная заболеваемость достигает 700\%о, а смертность 24,2-177,4\% [7, 8, 9].

В последние годы прогрессивно возрастает частота встречаемости СЗРП в популяции беременных. Это связано как с улучшением антенатальной диагностики, так и с нестабильностью социально-экономических условий в современном обществе [3].

Внедрение в практическое здравоохранение современных диагностических технологий (ультразвуковое исследование, допплерометрия, кар- диотокография) позволило снизить число детей с замедлением роста и недостаточностью питания $[6,9]$. Однако высокая заболеваемость и летальность среди новорожденных свидетельствует о том, что существующие способы ранней диагностики несовершенны, методы лечения недостаточно эффективны. Стандартной схемы лечения существовать не может вследствие индивидуального сочетания этиологических факторов и патогенетических механизмов развития данного осложнения. Подбор препаратов следует проводить индивидуально и дифференцированно в каждом конкретном случае с учетом степени тяжести и длительности осложнения, этиологических факторов и патогенетических механизмов, лежащих в основе этой патологии. Индивидуального подхода требуют дозировка препаратов и продолжительность их применения. Следует обращать внимание на устранение побочного действия некоторых лекарственных средств $[1,5$, $10,11]$.

Одним из ведущих патогенетических механизмов формирования СЗРП являются нарушения маточно-плацентарного кровотока (МПК) и фето- 
плацентарного кровотока (ФПК), сопровождающиеся повышением вязкости крови, гиперагрегацией эритроцитов и тромбоцитов, расстройством микроциркуляции и сосудистого тонуса $[1,2,5]$. В связи с этим важное место в лечении занимают ангиопротекторные препараты, улучшающие кровоток, реологические и коагуляционные свойства крови, перфузию тканей, снабжение их кислородом и питательными веществами $[3,4]$.

Исходя из вышеизложенного, цель работы представляет собой сравнительный анализ фармакологической эффективности широко используемых ангиопротекторных препаратов «Пентоксифиллин» ${ }^{\circledR}$ и «Флебодиа 600» ${ }^{\circledR}$ по результатам ультразвукового, допплерометрического и кардиотокографического исследований после проведенного лечения синдрома задержки роста плода.

\section{МАТЕРИАЛЫ И МЕТОДЫ ИССЛЕДОВАНИЯ}

Проведено ретроспективное и проспективное обследование 80 беременных женщин на сроках гестации от 28 до 36 недель. Критериями включения пациенток в исследование являлись: одноплодная беременность на сроке гестации от 28 до 36 недель, наличие синдрома задержки развития плода 1 и 2 степени, асимметричная форма задержки развития плода. Критерии исключения: многоплодная беременность, синдром задержки развития плода 3 степени, симметричная форма задержки развития плода, экстрагенитальная патология у беременной женщины в стадии декомпенсации, диагностированные пороки развития плода.

Беременные были разделены на 2 клинические группы. После получения добровольного

информированного согласия на участие в исследовании, беременные I группы получали «Пентоксифиллин» ${ }^{\circledR}$ в/в капельно в дозе 100 мг в 200-400 мл изотонического раствора натрия хлорида 1 раз в день, 5-7 инъекций на курс через день; II группа (40 человек) - принимали препарат «Флебодиа 600» ${ }^{\circledR}$ по 1 таблетке $(600$ мг) 1 раз в день утром натощак в течение 4 недель.

Статистическую обработку данных проводили с помощью стандартных пакетов прикладных программ Exel (Microsoft, 2007). При расчетах количественных изменений, произошедших в одной группе до и после лечения, использовались параметрический (критерий Стьюдента) и непараметрический (критерий Уилкоксона) методы. Оценка достоверности различий между группами выполнена при помощи U-критерия МаннаУитни. Полученные результаты выражались в форме среднее арифметическое (M) \pm ошибка среднего (m). Статистически значимым для всех показателей считался критерий достоверности $\mathrm{p}<0,05$.

\section{РЕЗУЛЬТАТЫ ИССЛЕДОВАНИЯ И ИХ ОБСУЖДЕНИЕ}

Возраст обследованных пациенток колебался от 15 до 47 лет и в среднем составил для беременных I группы 26,78 $\pm 2,12$; II группы $26,75 \pm 2,12$. Юных первородящих в I группе было 2,5\% (1), во II группе - 5\% (2). Возрастных первородящих в I группе 22,5\% (9), во II группе $17,5 \%$ (7). Преобладающее большинство женщин было в возрасте 21-29 лет - 76,3\% (61). Пациентки групп исследования были сопоставимы между собой по особенностям анамнеза, соматическому и гинекологическому статусам, репродуктивной функции.

Таблица 1

Особенности эхографической картины пациенток групп сравнения до фармакологической коррекции

\begin{tabular}{|c|c|c|c|c|c|c|c|c|}
\hline \multirow{2}{*}{$\begin{array}{c}\text { Эхографические } \\
\text { маркеры }\end{array}$} & \multicolumn{4}{|c|}{$\begin{array}{l}\text { I группа }(\mathrm{n}=40) \\
\text { абс. числа }(\%)\end{array}$} & \multicolumn{4}{|c|}{$\begin{array}{c}\text { II группа }(\mathrm{n}=40) \\
\text { абс. числа }(\%)\end{array}$} \\
\hline & $\begin{array}{r}28-30 \\
\text { недель } \\
\end{array}$ & $\begin{array}{c}\text { 30-32 } \\
\text { недели }\end{array}$ & $\begin{array}{c}\text { 32-34 } \\
\text { недели }\end{array}$ & $\begin{array}{r}\text { 34-36 } \\
\text { недель }\end{array}$ & $\begin{array}{r}28-30 \\
\text { недель }\end{array}$ & $\begin{array}{c}\text { 30-32 } \\
\text { недели }\end{array}$ & $\begin{array}{c}\text { 32-34 } \\
\text { недели }\end{array}$ & $\begin{array}{c}\text { 34-36 } \\
\text { недель }\end{array}$ \\
\hline $\begin{array}{l}\text { Плацента с дополни- } \\
\text { тельными дольками }\end{array}$ & $1(2,5)$ & -- & -- & -- & $1(2,5)$ & -- & -- & -- \\
\hline Плацентомегалия & $2(5,0)$ & $3(7,5)$ & $2(5,0)$ & $4(10,0)$ & $2(5,0)$ & $5(12,5)$ & $4(10,0)$ & $3(7,5)$ \\
\hline Гипоплазия плаценты & $1(2,5)$ & $1(2,5)$ & $3(7,5)$ & $2(5,0)$ & $1(2,5)$ & $4(10,0)$ & $1(2,5)$ & $2(5,0)$ \\
\hline $\begin{array}{l}\text { Преждевременное } \\
\text { созревание плаценты }\end{array}$ & $2(5,0)$ & $2(5,0)$ & $8(20,0)$ & $\begin{array}{c}17 \\
(42,5) \\
\end{array}$ & $2(5,0)$ & $3(7,5)$ & $\begin{array}{c}12 \\
(30,0)\end{array}$ & $\begin{array}{c}16 \\
(40,0) \\
\end{array}$ \\
\hline Кальциноз плаценты & $1(2,5)$ & $2(5,0)$ & $2(5,0)$ & $7(17,5)$ & $1(2,5)$ & $1(2,5)$ & $3(7,5)$ & $5(12,5)$ \\
\hline $\begin{array}{l}\text { Расширение } \\
\text { межворсинчатого } \\
\text { пространства }\end{array}$ & $5(12,5)$ & $4(10,0)$ & $\begin{array}{c}10 \\
(25,0)\end{array}$ & $\begin{array}{c}15 \\
(37,5)\end{array}$ & $4(10,0)$ & $\begin{array}{c}12 \\
(30,0)\end{array}$ & $9(22,5)$ & $\begin{array}{c}12 \\
(30,0)\end{array}$ \\
\hline СЗРП І степень & \multicolumn{4}{|c|}{$29(72,5)$} & \multicolumn{4}{|c|}{$32(80,0)$} \\
\hline СЗРП II степень & \multicolumn{4}{|c|}{$11(27,5)$} & \multicolumn{4}{|c|}{$8(20,0)$} \\
\hline
\end{tabular}


Таблица 2

Сравнительный анализ показателей эхографической картины пациенток групп исследования после фармакологической коррекции

\begin{tabular}{|c|c|c|c|c|c|c|c|c|}
\hline \multirow{2}{*}{$\begin{array}{c}\text { Эхографические } \\
\text { маркеры }\end{array}$} & \multicolumn{4}{|c|}{$\begin{array}{c}\text { I группа }(\mathrm{n}=40) \\
\text { абс. числа (\%) }\end{array}$} & \multicolumn{4}{|c|}{$\begin{array}{c}\text { II группа (n=40) } \\
\text { абс. числа }(\%)\end{array}$} \\
\hline & $\begin{array}{c}28-30 \\
\text { недель }\end{array}$ & $\begin{array}{c}30-32 \\
\text { недели }\end{array}$ & $\begin{array}{c}32-34 \\
\text { недели }\end{array}$ & $\begin{array}{c}34-36 \\
\text { недель }\end{array}$ & $\begin{array}{c}28-30 \\
\text { недель }\end{array}$ & $\begin{array}{c}30-32 \\
\text { недели }\end{array}$ & $\begin{array}{c}32-34 \\
\text { недели }\end{array}$ & $\begin{array}{c}34-36 \\
\text { недель }\end{array}$ \\
\hline $\begin{array}{l}\text { Плацента с } \\
\text { дополнительными } \\
\text { дольками }\end{array}$ & $1(2,5)$ & -- & -- & -- & $1(2,5)$ & 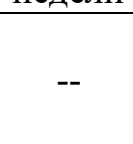 & 11 & 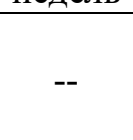 \\
\hline Плацентомегалия & $1(2,5)$ & $1(2,5)$ & $1(2,5)$ & $4(10,0)$ & -- & -- & -- & -- \\
\hline Гипоплазия плаценты & $1(2,5)$ & $1(2,5)$ & $3(7,5)$ & $2(5,0)$ & -- & -- & $1(2,5)^{*}$ & $1(2,5)$ \\
\hline $\begin{array}{l}\text { Преждевременное } \\
\text { созревание плаценты }\end{array}$ & $2(5,0)$ & $2(5,0)$ & $6(15,0)$ & $\begin{array}{c}17 \\
(42,5)\end{array}$ & $2(5,0)$ & $\begin{array}{c}10 \\
(25,0)^{*}\end{array}$ & $\begin{array}{c}12 \\
(30,0)^{*}\end{array}$ & $\begin{array}{c}7 \\
(17,5)^{*}\end{array}$ \\
\hline Кальциноз плаценты & $1(2,5)$ & $2(5,0)$ & $2(5,0)$ & $7(17,5)$ & $1(2,5)$ & $1(2,5)$ & $3(7,5)$ & $5(12,5)$ \\
\hline $\begin{array}{l}\text { Расширение } \\
\text { межворсинчатого } \\
\text { пространства }\end{array}$ & $3(7,5)$ & $2(5,0)$ & $9(22,5)$ & $\begin{array}{c}15 \\
(37,5)\end{array}$ & -- & -- & $1(2,5)^{*}$ & $2(5,0)^{*}$ \\
\hline СЗРП отсутствует & \multicolumn{4}{|c|}{--} & \multicolumn{4}{|c|}{$22(55,0)$} \\
\hline СЗРП І степень & \multicolumn{4}{|c|}{$30(75,0)$} & \multicolumn{4}{|c|}{$14(35,0)$} \\
\hline СЗРП ІІ степень & \multicolumn{4}{|c|}{$10(25,0)$} & \multicolumn{4}{|c|}{$4(10,0)$} \\
\hline
\end{tabular}

Примечание: * - p<0,05 показатель достоверности разности результатов между соответствующими подгруппами групп I и II

С целью получения информации о функциональных резервах фетоплацентарного комплекса всем пациенткам проводили ультразвуковое исследование (УЗИ), которое включало в себя плацентографию, фетометрию, оценку околоплодных вод. Эхографическое и допплерометрическое исследования проводили в сроки 28-36 недель беременности.

Ультразвуковое исследование, выполненное перед началом терапии, выявило особенности, представленные в таблице 1. При анализе полученных данных статистически значимой разницы по выявленным эхографическим маркерам ФПН и частоте случаев СЗРП в группах исследования не обнаружено, что делает группы сопоставимыми между собой и позволяет провести сравнительный анализ и объективно выявить лучший результат после двух разных схем лечения.

С целью контроля результатов проводимой терапии, УЗИ регулярно выполняли всем женщинам с частотой 1 раз в неделю (за время лечения выполнено не менее 4 УЗИ каждой женщине). На фоне проводимой терапии выявлена положительная динамика в обеих группах исследования. Однако по некоторым показателям (частота случаев плацентомегалии и гипоплазии плаценты, расширение межворсинчатого пространства и частота случаев СЗРП) достоверно лучшие результаты получены во II группе $(p<0,05)$. Полученные результаты свидетельствуют о благоприятном влиянии препарата «Флебодиа 600» ${ }^{\circledR}$ на внутриутробное развитие плода, что клинически проявляется нормализацией фетометрических показа- телей при ультразвуковом исследовании. Результаты представлены в таблице 2.

Всем беременным проводили допплеровское исследование кровотока в маточных артериях, артериях пуповины и сосудах плода. Характер гемодинамики в артериях пуповины позволяет судить о состоянии фетоплацентарного кровотока и о микроциркуляции в плодовой части плаценты. Для диагностики нарушения маточноплацентарного кровотока проводят исследования в маточных артериях с двух сторон. Срок беременности на момент исследования в среднем составил $31,2 \pm 0,4$ недели в I группе и $32,1 \pm 0,6$ недели во II группе. В таблице 3 представлены сравнительные результаты допплерометрии в группах исследования до и после фармакологической коррекции.

По данным допплерометрии, выполненной после лечения, установлено уменьшение значений индексов резистентности маточных артерий и артерий пуповины плода, по сравнению с исходными величинами. Следует отметить, что у пациенток, получавших «Пентоксифиллин» ${ }^{\circledR}$, достоверно лучшие результаты получены при исследовании правой маточной артерии и артерии пуповины плода, а у пациенток, принимавших препарат «Флебодиа 600» ${ }^{\circledR}$, - достоверно в большем проценте случаев уменьшились значения индекса резистентности всех исследуемых сосудов $(\mathrm{p}<0,05)$. Полученные данные демонстрируют различие в фармакокинетике этих препаратов: «Пентоксифиллин» ${ }^{\circledR}$ оказывает положительное действие на маточный и плацентарный кровоток, 
Сравнительный анализ данных допплерометрии пациенток обследуемых групп до лечения и после его завершения

\begin{tabular}{|c|c|c|c|c|}
\hline \multirow{2}{*}{ Параметр } & \multicolumn{2}{|c|}{ І группа $(\mathrm{n}=40)$} & \multicolumn{2}{c|}{ II группа (n=40) } \\
\cline { 1 - 5 } & До лечения, $\mathrm{M} \pm \mathrm{m}$ & $\begin{array}{c}\text { После лечения, } \\
\mathrm{M} \pm \mathrm{m}\end{array}$ & До лечения, $\mathrm{M} \pm \mathrm{m}$ & $\begin{array}{c}\text { После лечения, } \\
\mathrm{M} \pm \mathrm{m}\end{array}$ \\
\hline IR a. uterine dextra & $0,67 \pm 0,01$ & $0,56 \pm 0,02^{*}$ & $0,66 \pm 0,01$ & $0,44 \pm 0,004^{* \#}$ \\
\hline IR a. uterine sinistra & $0,65 \pm 0,01$ & $0,58 \pm 0,02$ & $0,64 \pm 0,01$ & $0,46 \pm 0,004^{* \#}$ \\
\hline IR a. umbilikalis & $0,72 \pm 0,04$ & $0,66 \pm 0,01^{*}$ & $0,75 \pm 0,04$ & $0,56 \pm 0,02^{* \#}$ \\
\hline
\end{tabular}

Примечание: * - достоверность различий показателей до и после лечения внутри одной группы (различия достоверны в сравнении с исходными данными $\mathrm{p}_{\text {д-п }}<0,05$ ); \# - достоверность различий показателей групп сравнения (различия достоверны при сравнении данных двух групп после лечения $\left.\mathrm{p}_{1-2}<0,05\right)$.

Таблица 4

Сравнительный анализ данных кардиотокографии и нестрессового теста плодов пациенток сравниваемых групп до и после лечения

\begin{tabular}{|l|c|c|c|c|}
\hline \multirow{2}{*}{ Критерий КТГ } & \multicolumn{2}{|c|}{$\begin{array}{c}\text { I группа } \\
\text { (n=40) }\end{array}$} & \multicolumn{2}{c|}{$\begin{array}{c}\text { II группа } \\
\text { (n=40) }\end{array}$} \\
\cline { 2 - 5 } & $\begin{array}{c}\text { До лечения, } \\
\text { М } \pm \mathrm{m}\end{array}$ & $\begin{array}{c}\text { После лечения, } \\
\mathrm{M} \pm \mathrm{m}\end{array}$ & $\begin{array}{c}\text { До лечения, } \\
\mathrm{M} \pm \mathrm{m}\end{array}$ & $\begin{array}{c}\text { После лечения, } \\
\mathrm{M} \pm \mathrm{m}\end{array}$ \\
\hline $\begin{array}{l}\text { Базальный ритм, ударов } \\
\text { в минуту }\end{array}$ & $127,5 \pm 10,1$ & $128,3 \pm 10,2$ & $129,3 \pm 10,2$ & $142,2 \pm 11,3^{* \#}$ \\
\hline $\begin{array}{l}\text { Амплитуда осцилляций, ударов } \\
\text { в минуту }\end{array}$ & $7,9 \pm 0,6$ & $8,2 \pm 0,6$ & $8,2 \pm 0,6$ & $10,8 \pm 0,8^{* \#}$ \\
\hline Частота осцилляций, в минуту & $4,4 \pm 0,4$ & $5,6 \pm 0,4$ & $4,6 \pm 0,4$ & $8,2 \pm 0,6^{* \#}$ \\
\hline $\begin{array}{l}\text { Акцелерации, количество за } 60 \\
\text { минут }\end{array}$ & $2,3 \pm 0,2$ & $2,5 \pm 0,2$ & $2,4 \pm 0,2$ & $4,1 \pm 0,3^{* \#}$ \\
\hline $\begin{array}{l}\text { Децелерации, количество за 60 } \\
\text { минут }\end{array}$ & - & - & - & - \\
\hline Суммарная оценка, баллы & $7,1 \pm 0,6$ & $7,4 \pm 0,6$ & $7,3 \pm 0,6$ & $9,1 \pm 0,7^{* \#}$ \\
\hline Реактивный НСТ & $35(87,5 \%)$ & $37(92,5 \%)$ & $36(90,0 \%)$ & $39(97,5 \%)$ \\
\hline Ареактивный НСТ & $5(12,5 \%)$ & $3(7,5 \%)$ & $4(10,0 \%)$ & $1(2,5 \%)^{* \#}$ \\
\hline $\begin{array}{l}\text { Двигательная активность плода } \\
\text { за 50 минут }\end{array}$ & $1,8 \pm 0,2$ & $2,2 \pm 0,2^{*}$ & $1,9 \pm 0,2$ & $2,4 \pm 0,2^{*}$ \\
\hline $\begin{array}{l}\text { Среднее увеличение ЧСС плода } \\
\text { на шевеление }\end{array}$ & $13,2 \pm 1,0$ & $15,5 \pm 1,2$ & $14,6 \pm 1,6$ & $18,2 \pm 1,4^{* \#}$ \\
\hline
\end{tabular}

Примечание: * - достоверность различий показателей до и после лечения внутри одной группы (различия достоверны в сравнении с исходными данными $\mathrm{p}_{\text {д-п }}<0,05$ ); \# - достоверность различий показателей групп сравнения (различия достоверны при сравнении данных двух групп после лечения $\left.\mathrm{p}_{1-2}<0,05\right)$.

тогда как «Флебодиа 600» ${ }^{\circledR}$ с одинаковой частотой и достоверностью улучшает показатели гемодинамики в обеих маточных артериях и в артерии пуповины плода.

Состояние плода оценивали с помощью антенатальной кардиотокографии плода, начиная с 30 недель беременности. При анализе оценивали базальный ритм, вариабельности базального ритма, наличие акцелераций и децелераций. Нестрессовый тест (НTC) считался положительным в случае регистрации двух и более акцелераций амплитудой не менее 15 ударов в минуту за 40 минут наблюдения.

По данным кардиотокографии плоды пациенток групп сравнения на фоне гемодинамических нарушений маточно-плацентарного и плодово- плацентарного кровотоков в 100\% находятся в состоянии хронической внутриутробной гипоксии. Суммарная балльная оценка КТГ ниже

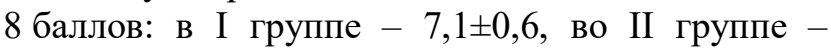
$7,3 \pm 0,6$. Низкая частота осцилляций и количество акцелераций: в I группе - 4,4 $\pm 0,4$ и $2,3 \pm 0,2$, во II группе - 4,6 $\pm 0,4$ и $2,4 \pm 0,2$. Наличие ареактивного НСТ у $12,5 \%$ (5) плодов в I группе, $10 \%$ (4) плодов во II группе. В таблице 4 представлены результаты до начала лечения и после его завершения. Анализируя полученные данные после завершения терапии, можно сделать вывод о наличии положительной динамики во всех группах исследования, однако достоверно лучшие результаты получены во II группе $(\mathrm{p}<0,05)$. 
Таблица 5

Сравнительный анализ данных физического развития ребенка при рождении в исследуемых группах

\begin{tabular}{|l|c|c|}
\hline \multicolumn{1}{|c|}{ Параметр } & $\begin{array}{c}\text { I группа } \\
(\mathrm{n}=40) \\
\mathrm{M} \pm \mathrm{m}\end{array}$ & $\begin{array}{c}\text { II группа } \\
\text { (n=40) } \\
\mathrm{M} \pm \mathrm{m}\end{array}$ \\
\hline Вес при рождении, г & $2094,25 \pm 165,68$ & $2598,25 \pm 205,56^{*}$ \\
\hline Рост при рождении, см & $42,68 \pm 3,43$ & $48,80 \pm 3,86^{*}$ \\
\hline Окружность головы, см & $29,55 \pm 2,50$ & $33,05 \pm 2,61^{*}$ \\
\hline Окружность грудной клетки, см & $27,15 \pm 2,31$ & $31,03 \pm 2,45$ \\
\hline Оценка по шкале Апгар & $6,76 \pm 0,53$ & $7,50 \pm 0,59^{*}$ \\
при рождении и через 5 минут & $7,65 \pm 0,62$ & $8,20 \pm 0,65^{*}$ \\
\hline
\end{tabular}

Примечание: * - p<0,05 показатель достоверности разности результатов между группами I и II.

По данным кардиотокографии отмечено увеличение базального ритма в I группе с 127,5 $\pm 10,1$ до $128,3 \pm 10,2$ удара в минуту, во II группе с $129,3 \pm 10,2$ до $142,2 \pm 11,3$ удара в минуту. Выявлено увеличение амплитуды осцилляций в I группе с 7,9 $\pm 0,6$ до $8,2 \pm 0,6$, во II группе с $8,2 \pm 0,6$ до $10,8 \pm 0,8$. Увеличилась частота осцилляций с

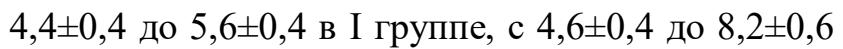
во II группе. Отмечено большее увеличение количества акцелераций во II группе исследования, по сравнению с I группой: 4,1 $\pm 0,3$ и $2,5 \pm 0,2$ соответственно. Ареактивный НСТ сохранился у 7,5\% (3) плодов в I группе, 2,5\% (1) плодов во II группе. Суммарная балльная оценка КТГ во II группе равна 9,1 $\pm 0,7$ балла, что достоверно выше по сравнению с показателями в $\mathrm{I}$ группе $7,4 \pm 0,6$ балла $(\mathrm{p}<0,05)$.

Полученные результаты свидетельствуют о положительном влиянии препарата «Флебодиа $600 »{ }^{\circledR}$ на внутриутробное состояние плода и повышение его адаптации к хронической гипоксии в большем проценте случаев по сравнению с препаратом «Пентоксифиллин» ${ }^{\circledR}$.

Физиологические роды были у $40 \%$ (16) женщин в I группе, 50\% (20) - во II группе. Преждевременные роды составили $35 \%$ (14) случаев в I группе, 20\% (8) - во II группе. Своевременные роды были у 65\% (26) женщин в I группе, 80\% (32) - во II группе. Срок родоразрешения у беременных I группы в среднем равен $36,8 \pm 0,8$ недели, во II группе $-37,8 \pm 0,7$ недели.

При анализе фетометрических показателей ребенка на момент рождения были выявлены следующие особенности. Во II группе вес новорожденных был достоверно больше, чем в I группе, и составил $2598,25 \pm 205,56$ и 2094,25 $\pm 165,68$ г соответственно $(\mathrm{p}<0,05)$. Средний рост детей при рождении во II группе в среднем составил $48,80 \pm 3,86$ см по сравнению с 42,68 $\pm 3,43$ см I группы $(\mathrm{p}<0,05)$. Окружность головы новорож-

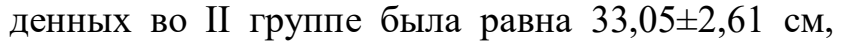
что больше по сравнению с полученными данными в I группе: $29,55 \pm 2,50$ см. Окружность грудной клетки детей не имела статистически значимых различий в I и II группах и составила $27,15 \pm$ 2,31 см и $31,03 \pm 2,45$ см соответственно. Средняя оценка по шкале Апгар на 1 и 5 минуте во II группе составила $7,50 \pm 0,59$ и $8,20 \pm 0,65$ и была выше, по сравнению с I группой, где оценка по шкале Апгар на 1 и 5 минуте составила 6,76 $\pm 0,53$ и 7,65 $\pm 0,62$ соответственно (табл. 5).

Вo II группе сразу после родоразрешения $10 \%$ (4) новорожденных были переведены в отделение реанимации и интенсивной терапии (ОРИТ), что было достоверно реже, чем в I группе, где перевод в реанимационное отделение потребовался 45\% (18) детей ( $<<0,05)$. Всех остальных детей сразу после рождения переводили в удовлетворительном состоянии на совместное пребывание с матерью, и они не требовали реанимационных мероприятий.

Резюмируя вышесказанное, можно сделать вывод, что препарат «Флебодиа 600» ${ }^{\circledR}$ положительно влияет на состояние плода и новорожденного. Курсовое лечение привело к рождению детей большей массы тела, достоверно реже диагностирована патология перинатального периода. В связи с тем, что данный лекарственный препарат природного происхождения, он не оказывает побочных эффектов на организм плода. В ходе исследования не было выявлено ни одного случая аллергизации новорожденных или появления отсроченных осложнений лекарственной терапии.

\section{ЛИТЕРАТУРА}

1. Каткова Н.Ю., Панова Т.В. Эффективность ангиопротекторов при лечении беременных с плацентарной недостаточностью // Consilium Medicum. 2006. - T. 8, № 2. - С. 28-30.

2. Кльчева О.И. Морфофункциональные особенности состояния фетоплацентарного комплекса у женщин с синдромом задержки развития плода // Coвременный научный вестник. - 2016. - Т. 10, № 1. - C. 54-58.

3. Кльчева О.И., Хурасева А.Б., Лазарева Г.А. Сравнительная оценка фармакологической эффективности ангиопротекторных препаратов в терапии 
фетоплацентарной недостаточности // Региональный вестник. - 2016. - № 4 (5). - С. 12-15.

4. Кузьмин В.Н. Фетоплацентарная недостаточность: проблема современного акушерства // Лечащий врач. - 2011. - № 3. - С. 50-54.

5. Логутова Л.С., Петрухин В.А., Ахвледиани К.Н. Эффективность ангиопротекторов при лечении беременных с плацентарной недостаточностью // Российский вестник акушера-гинеколога. - 2007. № 7 (2). - C. 45-50.

6. Проданова Е.В., Рогожина И.Е., Чехонацкая М.Л., Гришаева Л.А. Сравнительная допплерометрическая оценка эффективности терапии беременных с фетоплацентарной недостаточностью // Российский вестник акушера-гинеколога. - 2011. - Т. 11, № 2. - С. 79-82.

7. Савельева Г.М., Куриер М.А., Клименко П.А. Интранатальная охрана здоровья плода. Достижения и перспективы // Акушерство и гинекология. 2005. - № 3. - С. 3-7.

8. Стрижаков А.Н. Синдром задержки роста плода: патогенез, диагностика, лечение, акушерская тактика. - М. : ГЭАОТАР-Медиа, 2012. - 115 с.

9. Стрижаков А.Н., Игнатко И.В., Давыдов А.И. Прогнозирование и ранняя диагностика синдрома задержки развития плода // Вопросы гинекологии, акушерства и перинатологии. - 2014. - Т. 13, № 4. - С. 5-11.

10. Стриженок Е.А., Гудков И.В., Страчунский Л.С. Применение лекарственных средств при беременности: результаты многоцентрового фармакоэпидемиологического исследования // Клин. микробиол. антимикроб. химиотер. - 2007. - Т. 9, № 2. C. 162-175.

11. Сухих Г.Т. Проблема фармакотерапии во время беременности // Федеральный справочник. Социальное развитие и демография, 2011. - С. 253-256. 